Session 2553

\title{
Student Outcomes and Experiences in a Freshman Engineering Design Course
}

\author{
Sandra Shaw Courter, Lyman Lyons, Susan Bolyard Millar, and Andrea Bailey \\ Learning through Evaluation, Adaptation and Dissemination (LEAD) Center \\ University of Wisconsin-Madison
}

\begin{abstract}
A group of seven University of Wisconsin-Madison engineering professors created and piloted a freshman introduction to engineering course with sixty-seven students in fall, 1994. The course concentrated on having freshmen work in teams to identify customer needs, find solutions, and design a final product for a genuine customer. Students in each of the seven lab sections first worked in small groups of three or four to create proposed solutions, then met as a whole-lab group to decide on a solution and design and test it. Students concluded the course with formal presentations to students, faculty and customers. An evaluation of the course based on extensive observations and interviews with students found that students experienced engineering in a personal, supportive, team-oriented environment. The course helped students make informed career decisions and develop a sense of professional identity as engineers. An analysis of retention data indicated that the students stayed in engineering through their freshman year at a higher than average rate of $96 \%$, compared to $75 \%$ in a control group. Eighteen of the twenty women were retained.
\end{abstract}

\section{Background}

In 1993 the University of Wisconsin-Madison College of Engineering set up the College Curriculum Committee to examine whether a gap existed between its engineering education program and the expectations of employers. The committee concluded there was indeed a gap, and identified the needs to retain more freshmen and increase the number of women and minorities in engineering. Simultaneously, Sandra Courter and Katherine Sanders began a teaching improvement project with six engineering faculty that would be Sanders' Industrial Engineering Ph.D. dissertation project. The faculty examined the learning experience, exploring ideas they could use to improve their teaching and student learning. The opportunity to put their ideas into practice came with an Advanced Research Projects Agency-funded Technology Reinvestment Project grant awarded to the Engineering Research Center for Plasma-Aided Manufacturing. The grant included funding for a new freshman introduction to engineering course beginning fall, 1994.

\section{The Fall 1994 Pilot Course}

The new course's faculty met during the summer of 1994 to plan the course. They set the goal of the course to provide freshmen engineering students with an experience that allows them to discover engineering by practicing engineering in a realistic situation. Having the students work in small teams on 
a real hands-on design project for a real customer was chosen as the basic structure of the course. "We chose design because we thought that would be a really good vehicle to bring in a lot of the things we thought were important for first year students to be exposed to, " explained one faculty member.

The sixty-seven students enrolled in the fall, 1994 initial course offering were given the task of designing access for physically handicapped people to buildings at the Old World Wisconsin historical site. The following goals were stated in the student course handbook:

- $\quad$ work constructively in a design team.

- $\quad$ learn some engineering principles and engineering language

- $\quad$ seek out, digest, and use information from diverse sources

- $\quad$ learn from and teach your colleagues

- $\quad$ get to know your customers: wheelchair users and building staff

- $\quad$ communicate your designs effectively

- $\quad$ understand the design environment (business, legal, social)

- $\quad$ keep a personal record of your design process and your learning

The course consisted of a 50 minute lecture and a three-hour lab each week, taught by seven faculty and seven senior student assistants. ${ }^{1}$ Faculty took turns giving lectures, and one faculty member and one senior assistant paired up to teach a lab section. Students in a lab section formed small groups of three to four to develop designs, then selected one design for further development as a whole-lab group of about ten students. The students kept a journal and prepared two presentations: their small group's design to the other lab members, and their whole-lab presentation to the course's students, faculty and customer. Students were encouraged to engage in a dialog with faculty and senior assistants through Email.

Students participated in peer and self assessment. Both faculty and senior assistants assessed the students' progress on the basis of observations in the lab and the quality of their journals and team presentations. In making these assessments, faculty and senior assistants emphasized students participating in the process of design and the progression of learning, not their attaining a "right answer" to the design problem.

\section{Course Evaluation Process}

The pilot fall 1994 course offering was evaluated by the University of Wisconsin-Madison's Learning through Evaluation, Adaptation and Dissemination (LEAD) Center. The purpose of the evaluation was to understand the effect of the new course on students, and was primarily based on the collection of qualitative information. Twenty-eight students, equally divided between male and female, were interviewed in the fourth week and at the end of the semester, the fourteenth week. In addition, the evaluators led one female and one male focus group discussion, with each group composed of one student from each lab section. Two lab sections were observed each week, as well as all the lectures. All students in the course completed a survey during the tenth week of the course. The individual interviews and focus group discussions were as open-ended as possible to ensure that the students' experiences, rather than the evaluators' conceptions, were the center of the conversation.

The evaluation also gave the faculty "real-time" feedback during and immediately after the semester. The LEAD Center evaluators held meetings with the faculty and senior assistants several times 
during the semester. At each meeting, faculty and evaluators discussed the evaluators' "work-in-progress" reports, and the faculty developed a set of "action items" to revise their plans during the semester. The LEAD Center completed a final report a month after the semester ended.

\section{Evaluation Results}

The focus of the evaluation was on the qualitative understanding of the students' experiences. Quantitative retention data based on the classifications of students at the end of the 1994-95 academic year were also analyzed. This analysis compared students who completed the course with students on the waiting list who could not enroll because of the limited course enrollment. The following data represent the classification of students as of June, 1995:

- $\quad$ Almost all of the 67 students completing the course $(96 \%)$ had an engineering classification. Of the 34 students on the waiting list, $75^{\prime} \%$ had an engineering classification.

- $\quad$ Females represented $30 \%$ of the course (20 students) and minorities less than 5\%. Eighteen of the twenty women completing the course had an engineering classification.

- $\quad 39 \%$ of the students who took the course had selected a specific engineering major, such as mechanical or civil, as compared to $25 \%$ of the waiting list students.

- Seven of the eight engineering majors were selected by students completing the course, as compared to five of the eight by students on the waiting list.

These data indicate that a higher than usual number of students completing the course were staying with engineering and had chosen a major. What accounts for these retention results? The qualitative information obtained from the interviews and focus group discussions with students suggests several reasons, presented below in terms of prevalent student experiences. These experiences are illustrated by the students' own descriptions (in italicized quotes) of what made the course important for them. Of particular note, an analysis of their interviews indicated that their experiences revolved around the teams they formed in the lab to formulate and construct their designs.

Student Experience 1: Students experienced engineering in a personal, supportive. team-oriented environment.

Teams were the most frequently mentioned part of the learning process by students. Many students found that teamwork allowed them to develop confidence. Some typical remarks:

Some people are outgoing right away, involved, show leadership, and then there's some people who are kind of shy, quiet, who just kind of sit in the corner. And I was pretty much one of those shy people to begin with. That's usually where I'm at, but I made myself get involved and it's a lot more fun when you get involved!

For myself, my confidence and self-esteem grew as the time went on, which is good. Usually in a large setting you 're just working and you are pretty much no one. You're just a number as I said before. Knowing that you actually are participating in and having a positive influence is just 
really nice to feel inside, to know that you're needed--that you're wanted.

The teams did not automatically function efficiently from the start, but went through a development phase as students got to know each other and learned to work together:

After awhile the people got a little more comfortable with everyone else and were more willing to listen to everyone and be more responsive to everyone.

At the beginning [the course was] kind of weird, you know, because you didn't really know anybody... but the last couple weeks it was just hilarious because we were all involved. We just had a great time!

Students often mentioned the personal contact with professors and senior assistants as a being a key element for them:

But this--with the size of these groups and the way it's set up, you get to know your senior assistants as well as your professors, and sort of like a family almost... It provides for a comfortable atmosphere and it's just a lot easier to learn when you 're not all up tight and alone.

Well, getting to know the professor and the senior assistants is a big thing, and them getting to know you.

The hands-on lab activities helped students get involved in the design process and with each other:

At the beginning people were taking things apart and they thought it was the greatest thing ever. Like you want to know how it works, you know. "Here, I'll show you this now. "You get what's inside and then find it and that was cool. 'Cause I didn 't know how it worked and that was really interesting.

Student Experience 2: Teamwork developed friendships which are crucial to freshmen who are new to campus.

And it's really nice to feel like you fit in, that you know people. You 're not a stranger. It just feels nice to have someone to say "Hi" to you!

Well, you 've had a common experience. You 've got something you can talk about--remember when you did this or that.

It kind of makes you feel like you already have a place here. Which as a freshman, this college is so big, so, I don 't know, you get kind of scared because you don 't really know where anything is and everything. It is kind of nice to come over here where some people actually know you.

\section{Student Experience 3: Students discovered that teamwork is effective and is a valuable real-world skill.}

That's the whole point of having engineers work together, because each of them are specialized in their respective fields. And that's why the teamwork aspect of this class is so important, because later on you 're going to have different engineers with specializations in other fields working 
together so they can share that expertise on subjects that they know.

Many students noted that working in teams allows each student to go beyond his/her individual capacities:

'Cause otherwise (without teamwork) you're just still going to be one person, limited to your capacity then.

Student Experience 4: Students discovered that thev learn best when thev are in a group and must be rest) onsible for their own learning and progress.

If someone proposed a certain change in the design and I didn't understand it right away, other people would join in and help explain it so I understood the whole thing. They wouldn 't just say, "Oh, forget it." They would make sure I understood it, and then I would do the same if I had an idea.

The faculty and senior assistants created an environment in which students learned from each other. The role of the instructors was to facilitate teamwork, motivate students, then get out of the way and let the students think for themselves:

That's why I think the whole course was more like - you teach yourselves. You learn from each other more than you do from the professor. He's just kind of there to supervise it.

So then he kind of started us off, and as he saw us getting into it... and we would just continue. ... We were like, "Wow, I don 't believe we 're doing this. He's not even here." We liked the way it was all on our own.

The design process encouraged students to becomes active learners:

One thing it did show me is that I think I learn best amongst a group of people sitting together discussing, rather than having a professor lecturing to a bunch of people.

Student Experience 5: The course helped students make a career choice and develop a sense of professional identity as engineers.

Many students indicated that the course helped them because it "showed different angles of what engineering is" and "reassured their direction":

Actually participating in an engineering project like this--seeing what it's really going to be like, actually participating in something rather that just reading out of a book-it really makes a difference in what you think.

Most students remarked about how the course gave them a "peek behind the scenes" of engineering:

You're actually going through what a real engineer does without being an engineer yet. That's why I think it's cool that this is my freshman year, so people understand what they're getting into... I never thought I would be able to feel what it's like to be an engineer so early. Like that 
actual nervousness with the presentation, that actual building without professors telling you what to do, but you decide what you want to do. I thought that was a big thing for me personally.

Throughout the semester students tried to picture themselves as engineers and valued the variety of sources in the course that gave them a glimpse of what being an engineer would be like. By the end of the first semester, many students said they felt comfortable in engineering:

I was going to switch to the business school. And I looked into the business school and stuff. And it seemed almost weird to want to switch because I already felt so comfortable here.

Several students found that the interactions and the problem-solving skills they developed in the design course affected how they felt about their future:

I like the idea of interaction and solving problems and I think that whatever I do with my life it's going to be part of that and I would say that this course will have helped. I still feel pretty strongly that I'm probably going into engineering, and that's the track I'm on right now full-steam.

That made me realize that all the work that we're going to be doing in college is going to pay off eventually. And we'11 find careers that we'11 hopefully enjoy, to a certain extent. And it also made me realize that we aren 't going to be locked up in some lab or in some office never to see another human face again.

Student Experience 6: Female students (30\% of the class) developed confidence and had a Positive introduction to what thev considered to be a traditionally male field of study.

Oh, very comfortable. Very, very comfortable. Everybody got along really well... the guys were the majority, I would just feel uncomfortable sort of, sometimes. They were really good about it, too. I was kind of scared to begin with, because I know engineering is such a male dominated field.

I went in there not really knowing much, being a girl [laughs], not knowing much about mechanical things and wood and putting things together, and now I've got some knowledge of building and some of the engineering things we learned.

As a further indication of their generally positive experience, many of the comments illustrating Student Experiences 1-5 above were from female students. Four of the seven senior assistants were female, which possibly contributed to the female students' successful experience.

\section{Discussion}

The students' experience of going through an open-ended design process as a team 'was the essential feature of the course. The interactions among team members helped students build confidence and self-esteem. Experiencing a realistic design project provided a context in which students could make informed decisions about pursuing an engineering career. The faculty and senior assistants represented a variety of engineering disciplines, and the senior assistants provided a bridge between the faculty and the freshmen students. The course gave students a shared experience and a series of successes as they discovered the engineering design process first hand, with a real project and a real customer. 
The faculty used the evaluation feedback meetings held during the semester to adjust their teaching as they came to better understand the effects of the course on their students. They recognized that their goals for students were still emerging, and revised their original goals after the fall 1994 pilot semester was completed. "We're in the early development stage," remarked one. The reformulated goals are:

- $\quad$ allow students to learn how to form and work in teams (team dynamics)

- $\quad$ provide the opportunity for a sequence of successful experiences for the student

- $\quad$ have students acquire a feeling (hands-on) of what engineering entails and might encompass

- develop design process skills on a "real" design project with "real" customers

- develop skills for hardware and software usage in the projects in an as-needed basis

- develop context for engineering curriculum, so students see connections among math, science and technology classes

- develop confidence in engineering as a career, particularly for students with little prior knowledge or experience in engineering-type activities

In comparing these goals with the ones from the first semester, one can see a shift from learning specific content and skills towards experiencing a process with other students and developing a sense of what engineering entails. These revised goals more accurately reflect the students' experiences and their descriptions of what they found valuable in the course: what they want and need to become engineers. The faculty anticipate that the goals and philosophy that emerged during and after the pilot semester will continue to evolve.

\section{Acknowledgements}

The course evaluation was sponsored by the Advanced Research Projects Agency-Technology Reinvestment Project grant "Diversity and Cultural Change: Manufacturing Engineering Education for the Future" to the Engineering Research Center for Plasma-Aided Manufacturing, under grant \#ECD8721545 (administered by the National Science Foundation). Additional support was provided by the University of Wisconsin-Madison's College of Engineering (through an IBM Quality Award), Graduate School, and LEAD Center (through a Hilldale Foundation grant from the Chancellor).

\section{References}

1. For a detailed description of the course see Corradini, M., Farrell, P., Mitchell, J., Marleau, R., Moskwa, J., Sanders, K., and Webster, J., "A Team-Based Design Course For Freshmen," Proceedings, 1995 ASEE Annual conference, ASEE, 1995. 


\section{Biographical Information}

SANDRA SHAW COURTER is Adjunct Assistant Professor, Department of Engineering Professional Development, College of Engineering, University of Wisconsin-Madison. She teaches technical communication courses to both undergraduate engineering students and practicing engineers, scientists, and technicians. She is director of the Technical Communication Certificate Program and program director of the Engineering Learning Center. Having earned a B.S. in English education, she is completing her doctoral dissertation in Educational Administration at UW-Madison, focusing on the impact of the freshman engineering design course on students and faculty. While gathering her research data, she worked at the Learning through Evaluation, Adaptation and Dissemination (LEAD) Center at the University of Wisconsin-Madison.

LYMAN LYONS is an Associate Researcher at the LEAD Center, University of WisconsinMadison. He holds degrees in chemistry (B. S.) and history of science (M.A.), and has taught high school science and conducted research in analytical chemistry. He is currently involved in research and evaluation projects in science education at the college level.

SUSAN BOLYARD MILLAR is Director of the Learning through Evaluation, Adaptation and Dissemination (LEAD) Center at the University of Wisconsin-Madison. The LEAD Center primarily conducts evaluation research in support of UW-Madison faculty efforts to improve undergraduate and graduate student learning. Dr. Millar received her B.A. in English Literature from William Smith College and her Ph.D. in anthropology from Cornell University. Among her publications is A Silent Success: Master's Education in the United States (1993, with C. F. Conrad \& J. G. Haworth).

ANDREA BAILEY is completing her doctoral dissertation in Political Science at the University of Wisconsin-Madison. She has a B.A. degree in psychology and an M.A. in political science, and has worked in educational evaluation projects at the Wisconsin Center for Education Research and the LEAD Center. 